\title{
Thermal profiles in pervious concrete during summer rain simulations
}

\author{
Alexandre Lorenzi ${ }^{1}$, Liv Haselbach ${ }^{2}$, Luiz Carlos Pinto da Silva Filho ${ }^{1}$ \\ Ângelo Simonetto Pessutto ${ }^{1}$, Gabrielle Bacelo Bidinotto ${ }^{1}$
}

\author{
${ }^{1}$ Laboratory for Testing and Modeling Structures - LEME - Av. Bento Gonçalves, 9500 - Prédio 43436, Porto Ale- \\ gre/RS - Brazil \\ e-mail: Alexandre.lorenzi@ufrgs.br, lcarlos66@gmail.com, angelo@pessutto.com.br,gbidinotto@gmail.com \\ ${ }^{2}$ Civil and Environmental Engineering, Lamar University, PO Box 10024, Beaumont, TX 77710, USA \\ e-mail: lhaselbach@lamar.edu
}

\begin{abstract}
Pervious concrete pavement systems may have many environmental benefits including the mitigation of heat island impacts. This mitigation is a complex combination of pervious concrete's insulating capability and its ability to store water which may provide evaporative cooling. However, the introduction of water may also bring heat into the system, where the system is the pervious concrete pavement layer over an underground aggregate bed for retention and/or detention of stormwater. This study involved three different mix design placements in southern Brazil on a hot sunny summer day. The experiment had a control section and two test spots where controlled artificial rain events were introduced at two times during the afternoon for each of the three placement types. The 'rain' initially brought heat from the surface into the pervious concrete layer. Subsequent evaporation cooled these interior pavement layers to levels similar to the control locations. This introduction of water into pervious concrete with very hot surface temperatures in the heat of the day is expected to be a severe condition for adding heat to the system through the flow of water. If water additions are made at different diurnal times, such as nighttime rain, they may provide similar evaporative benefits with less heat transfer into the system via the water phase, and thus even more cooling of the system. These experiments reinforce the conclusion that pervious concrete may be a cool pavement during summer conditions, even under extreme conditions when surface heated stormwater enters the system.
\end{abstract}

Keywords: pervious concrete pavement, stormwater, heat island

\section{INTRODUCTION}

Pervious concrete is an alternative pavement that provides not just a structured surface for vehicular and pedestrian purposes, but it also has many other benefits, notably its use for stormwater management and the added benefit that it may provide for mitigation of the urban heat island. The heat island effect occurs when manmade materials such as pavements and buildings store daytime heat, causing elevated temperatures in the urban area as compared to nearby natural areas [1]. Strategies to reduce some of the impacts include using materials with a high solar reflectance index, or increasing trees and other shading devices [2,3]. Some studies argue that pervious concrete has an additional 'cooling' capability of storing water which may evaporate and then provide evaporative cooling [4]. In fact, managing stormwater locally with a permeable pavement instead of using traditional pavements and stormwater systems that direct the waters to other areas may also help as increased fog can also lower the temperature in the summer [5].

In addition, it has been shown that the porous nature of the permeable pavement layer can serve as an insulating layer, preventing additional heat transfer deeper under the pavement during hot summertime conditions [6], or in the colder months, restricting heat transfer out of the pavement resulting in shallower frost depths [7]. The entire system may aid in mitigating the heat island effect with the porous aggregate storage bed under the pervious concrete layer also serving as an insulating layer for the ground below, with the system behaving similar to more reflective traditional concrete $[8,9]$.

The heat island benefits shown in these aforementioned studies occurred despite the fact that the surface of pervious concrete may become much hotter than is found in traditional concrete, mainly due to the lower reflectivity of the porous surface and the decreased mass for heat storage. For instance, Balbo and Severi [10] over an entire year in São Paulo, Brazil measured surface temperatures of traditional concrete 
pavement with a maximum of $52.5^{\circ} \mathrm{C}$. A two-day study in Greenville, South Carolina found surface temperatures of pervious concrete rose to $61{ }^{\circ} \mathrm{C}$ while the neighboring surface of the traditional concrete pavement only reached $49^{\circ} \mathrm{C}$ under similar conditions [6].

However, stormwater may also bring heat into a pervious concrete system through the flow of warmer water into the pervious concrete and the aggregate bed below during a precipitation event. In the summer, stormwater heated from the surrounding pavements may be substantially warmer than the below ground temperatures. This adds more complexity to the system, with conductive heat flow through the solids, evaporative cooling with convective transfer upward, and also convective flow of heat carried in the water as it flows downward. An earlier study in Iowa showed that nighttime rain provided added cooling with a pervious concrete system as compared to a traditional concrete pavement system [8,9]. A laboratory simulation by Nemirovsky et al. [11] evaluated the overall evaporation in a column of pervious concrete over an aggregate storage bed under many conditions. It was shown that there can be evaporation from the storage bed also, particularly when the storage levels are high and the water surface in the storage bed is closer to the pervious concrete layer. Their research indicates that under some conditions evaporation, even in the storage bed can be a significant part of the hydrologic cycle. It is expected that for smaller rain events, much of the water might remain in the pervious concrete layer, thus allowing for evaporation to be a large portion of the water mass balance when investigating the system and evaporation not only impacts the water mass balance, but also the heat balance.

The question therefore remains as to the impacts of heated daytime rain on heat island mitigation. It is hypothesized that daytime rain during a hot summer day will not have a deleterious impact on heat island mitigation. Even though water may gain heat from the surface and enter the system, the overall heat through the depth of the system may still remain the same if the added heat is only from the pervious concrete surface, with the added benefit of evaporative cooling as the sun heats the pavement layer.

A preliminary study was performed on the Campus do Vale of the Federal University of Rio Grande do Sul (UFRGS) in Porto Alegre, Brazil, using a small section of a parking area that had been replaced with a $15 \mathrm{~cm}$ deep pervious concrete layer over a $20 \mathrm{~cm}$ deep layer of aggregate in January 2015. The intention was to design an experiment that might be effective in validating the performance of pervious concrete with respect to heat island mitigation with the addition of water. These preliminary tests were then performed in April 2015 [12]. Three sections of the pavement were designated for testing, all made with a 5.5/1 mass ratio of aggregate to cement. One section would serve as a control and two sections for duplicate testing of the introduction of water. At each location a rectangular area of $305 \mathrm{~mm}$ by $660 \mathrm{~mm}$ was outlined, with thermal sensors installed at the mid-depth and at the bottom of the pervious concrete layer in the middle of the rectangle. On April 27th, temperatures were recorded using the sensors from late morning till late afternoon, and surface temperatures recorded periodically using a thermal gun. Ambient temperatures were in the low 20 s on the centigrade scale, with fairly sunny skies and a light breeze. Approximately 45 minutes into the experiment, two liters of water were poured evenly over each of the designated areas in the two test sections. This amount of water was expected to fill the voids in the pervious concrete layer with little water draining below. The calculation for the water volume was based on previous laboratory research by one of the authors where a pervious concrete layer with a depth of approximately $18 \mathrm{~cm}$ would hold an application of $1 \mathrm{~cm}$ of rainwater applied to the top prior to water draining through the bottom [13]. The water applied in the April 2015 preliminary study was left outside in the shade until its temperature was near ambient. The results are compiled from this preliminary study are summarized in Figure 1 [12]. 


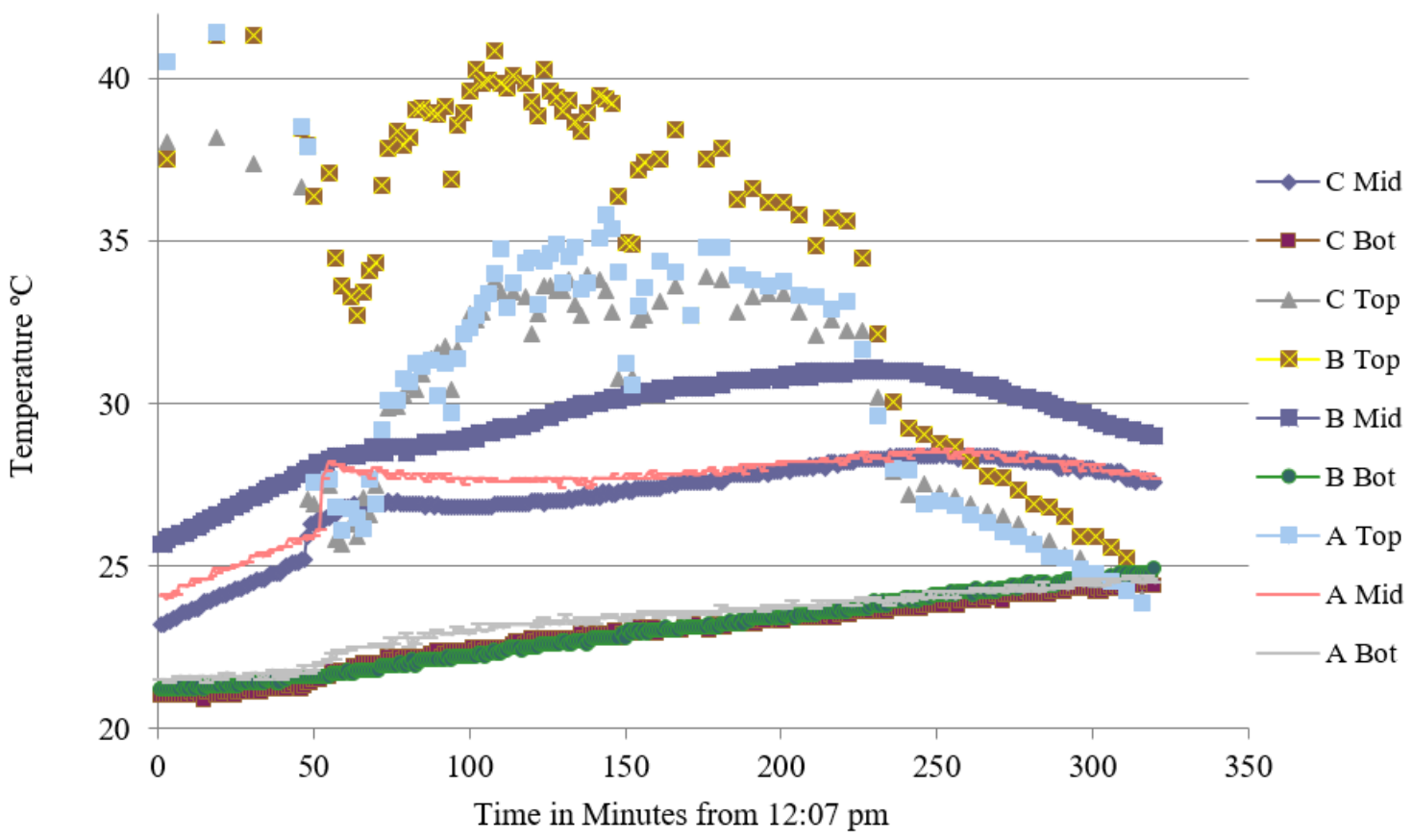

Figure 1: Preliminary experiment results. $B$ is the control while $A$ and $C$ had water introduced. Temperatures were recorded on the top (Top), in the middle of the pervious concrete layer (Mid) and just below the layer (Bot). Data is from Lorenzi et al. [12].

As can be seen in Figure 1, the surface temperature of the pervious concrete was significantly higher than the air temperature. It also varied, even without the application of water. This was frequently correlated with intermittent cloud cover, during which the surface temperature would cool rapidly in the breeze. The surface temperature of the two test sections (A and C) dropped even more dramatically when the water was introduced, at which time the temperature in the middle of the pervious concrete at these two locations jumped higher, with only a very slight increase in the temperature at the bottom locations. Note that cloud cover also was evident at the time the water was introduced producing a drop in the surface temperature of B, but without the sharp increase in the middle temperature of B. In comparison, cloud cover between 200 and 250 minutes resulted in similar large decreases in surface temperature of all three sections, without sharp jumps in the interior temperatures.

The much smaller temperature increases at the bottoms of $\mathrm{A}$ and $\mathrm{C}$ at the time the water was introduced imply that this amount of water was sufficient to go all the way through the pervious concrete layer, but probably not much farther. Thus, it was agreed that this experimental method appeared to be a good protocol for studying the impacts of heat from surface heated water in the pervious concrete layer. An experiment was then planned for similar testing during the summer in Porto Alegre, when temperatures would be even warmer, allowing for even hotter water to be introduced into the pervious concrete layer.

This preliminary test also provided much insight. As can be seen in the middle three lines in Figure 1, there is little or no difference in the change in temperature from the start to the end of the testing period between the three sections, whether the control section or the test sections, even though there were significant differences at the point when the water was introduced. Thus, the overall heat impacts seem similar. Note though, that due to shading from clouds and trees, and differences in the sensor readings, the absolute temperatures might be different. In addition, the bottom temperatures in the three sections are nearly identical, with or without the introduction of water [12].

\section{MATERIALS AND METHODS}

This existing pervious concrete pavement parking area located at the Federal University of Rio Grande do Sul (UFRGS) in Porto Alegre, Brazil also had a section installed in 2014 with a pervious concrete portion made with a 7.1/1 aggregate to cement mass ratio. This was later determined in laboratory experiments to not have sufficient cement for adequate longterm strength, but the portion in the parking area remained in good 
condition. In August 2015, a third portion of pervious concrete was also installed near the two existing areas with a 4/1 aggregate to cement ratio. All three pavement mixes were installed to the same depth of $15 \mathrm{~cm}$ and placed over a $20 \mathrm{~cm}$ layer of aggregate storage below. Reasons for using the three mix designs were to determine longterm durability with less and less cement to lower costs. However, this also provided for three areas with different porosities, with the denser mix design (4/1) assumed to be less porous than the 5.5/1 mix design, and even more so than the 7.1/1 design. The aggregate used in the pervious concrete layer was local basalt and the cement used was the typical cement/fly ash mix locally available.

Temperature sensors were installed in the two additional pervious concrete areas in an identical manner as was used in the preliminary testing in April 2015, i.e. at each new area three new rectangles were outlined with tape on the surface starting at the pavement edge with a $305 \mathrm{~mm}$ width and going $660 \mathrm{~mm}$ into the pavement area. These three rectangles were separated by at least $300 \mathrm{mms}$ widthwise so that neighboring rectangles would have limited impact on each other. Thermal sensors were installed at the mid-depth and at the bottom of the pervious concrete layer in the middle of each of the rectangles. Thus, each type of pervious concrete had a control and two test sections, with sensors installed at mid-depth and at the bottom of the pervious concrete layer. Surface temperatures were again planned to be taken with a thermal gun, with three temperatures averaged at each time step, near the center of each rectangle. The overall experimental plan would therefore have three controls and six test areas. The sections with the 5.5/1 mix design were labeled A, $\mathrm{B}$ and $\mathrm{C}$. B was the control while $\mathrm{A}$ and $\mathrm{C}$ were the test sections that would receive water. The sections with the 4/1 mix design were labeled D, E and F. F was the control while D and E were the test sections that would receive water. The sections with the 7.1/1 mix design were labeled G, H and I. H was the control while $\mathrm{G}$ and I were the test sections that would receive water. The locations are depicted in the photograph in Figure 2 with the white papers temporarily located within in each rectangle for better photograph clarity.

Figure 2: Sections A, B and C are in the middle, D, E and F to the left and G, H and I are to the right. Note the tree

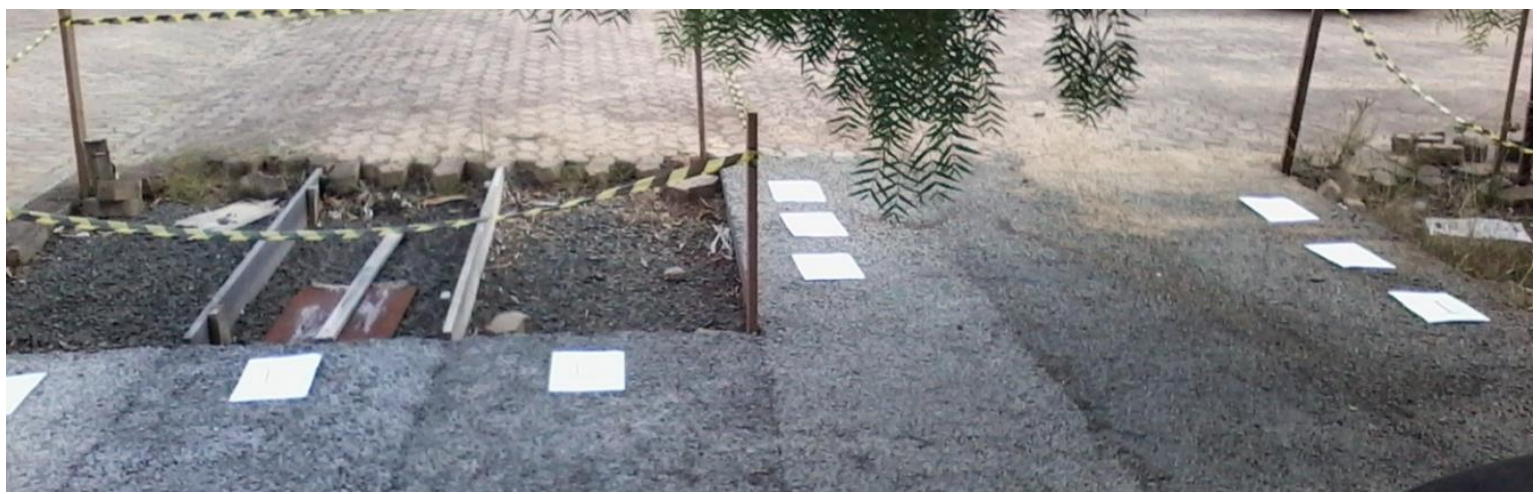

branches in the foreground which provided differential shading. To the right is NNE. A is farthest west, $\mathrm{F}$ is farthest south and I farthest east.

The experiments were performed on January $19^{\text {th }}, 2016$, in the middle of a Brazilian summer, in a manner similar to the test protocol of April $27^{\text {th }}, 2015$. During the test, the temperature fluctuated between $25^{\circ} \mathrm{C}$ and $27^{\circ} \mathrm{C}$, the humidity ranged between $66 \%$ and $74 \%$ and the wind varied from $24 \mathrm{~km} / \mathrm{h}$ to $33 \mathrm{~km} / \mathrm{h}$.

Table 1: Forecast for the test hours.

\begin{tabular}{c|c|c|c|c}
\hline TIME & TEMPERATURE $(\mathbf{-} \mathbf{C})$ & WIND $($ KM/H) & HUMIDITY (\%) & FORECAST \\
\hline $11: 00$ & 25.0 & 24.0 & 74.0 & Mostly cloudy \\
\hline $12: 00$ & 26.0 & 20.0 & 70.0 & More clouds than sun \\
\hline $13: 00$ & 26.0 & 28.0 & 70.0 & Partly sunny \\
\hline $14: 00$ & 26.0 & 30.0 & 74.0 & Broken clouds \\
\hline $15: 00$ & 26.0 & 32.0 & 70.0 & Partly sunny \\
\hline $16: 00$ & 27.0 & 30.0 & 66.0 & Broken clouds \\
\hline $17: 00$ & 26.0 & 33.0 & 70.0 & Partly sunny \\
\hline
\end{tabular}


This test protocol meant that temperatures in the mid-depth and bottom of each of the three outlined rectangular sections in each of the three different pervious concrete areas were recorded every minute, while surface temperatures were manually recorded periodically near the center of the surface of the nine outlined rectangular sections. The thermal sensors started recording at all 18 sensor locations around 11:21 am and were logged every minute. Surface temperatures at the 9 surface locations were initiated approximately 25 minutes later, and an average of three temperatures recorded every 15 minutes. The water was added at each of the two test sections in all three pervious concrete areas approximately three hours into the experiments, when it would be expected to be near the hottest part of the day. This water had been allowed to warm to ambient air temperature and two liters were poured evenly over the outlined rectangles in each of the six test sections in order to mimic stormwater being warmed by the hot pavement surface. Water was not added to the control section in all three of the pervious concrete areas at any time. Water was again added approximately two hours later in the same manner to the test sections of the three different placements, but not to the three control sections. The intention of this second addition of water was to add even more heat to the test sections prior to the cooling of the evening. The experiment ended at 5:08 pm on the same day.

\section{RESULTS}

Figures 3, 4 and 5 depict the results for all three areas of pervious concrete during the entire testing period. Figure 3 shows the data for the original section with the 5.5/1 design mix, as previously tested in the preliminary experiments in April 2015 and now shown for the data in the summer during January 2016. For the 5.5/1 design, Section B is the control. Figure 4 depicts the section with the 4/1 mix design with Section F as the control. Figure 5 shows the temperature data for the $7.1 \mathrm{mix}$ design with Section $\mathrm{H}$ as the control. Surface temperatures varied for all the nine sections in the first three hours, prior to the wetting test. Sections $\mathrm{A}$ and $\mathrm{B}$ reached temperatures over $55^{\circ} \mathrm{C}$, while Sections $\mathrm{C}, \mathrm{E}, \mathrm{F}, \mathrm{G}$ and $\mathrm{H}$ had maximum surface temperatures hovering around $50^{\circ} \mathrm{C}$. Sections D and I only had maximum surface temperatures in the $30 \mathrm{~s}$ during this earlier time period, however, later in the day their maximum temperatures reached around $45^{\circ} \mathrm{C}$ as the sun shifted in the sky. These initial variations are partially due to shading and the angle of the sun relative to the tree location. Additional information on the locations of the sections with respect to the tree and cardinal directions is as previously provided in Figure 2. In addition, each section had varying porosities due to the non-homogeneous nature of pervious concrete, and different amounts of clogging and wear from field use, which might all impact the surface temperatures. Despite these differences, similar behaviors were apparent in all three different types of pervious concrete for all six of the wetted sections, particularly at the times of the additions of water, although the temperature values tended to be higher in the interior and bottom portions of the pervious concrete corresponding to the sections which had higher surface temperatures at that particular time, as would be expected. Likewise, the control sections showed similar behaviors, slowly heating up in the middle, and even more slowly at the bottom for all the three cases. 


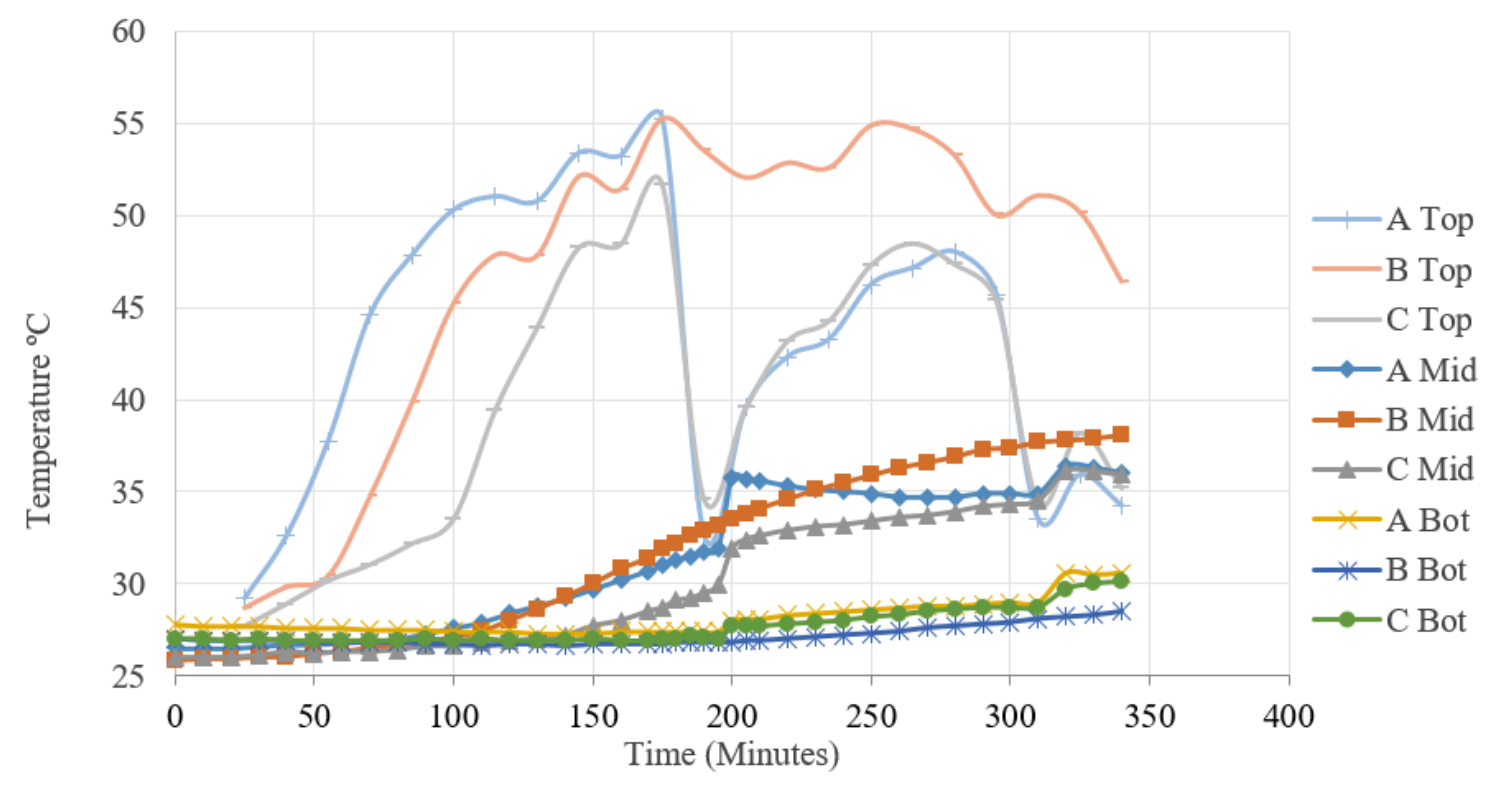

Figure 3: Top, middle and bottom temperatures recorded for the three sections using the 5.5/1 mix design in January 2016. B is the control. A and $\mathrm{C}$ had water added.

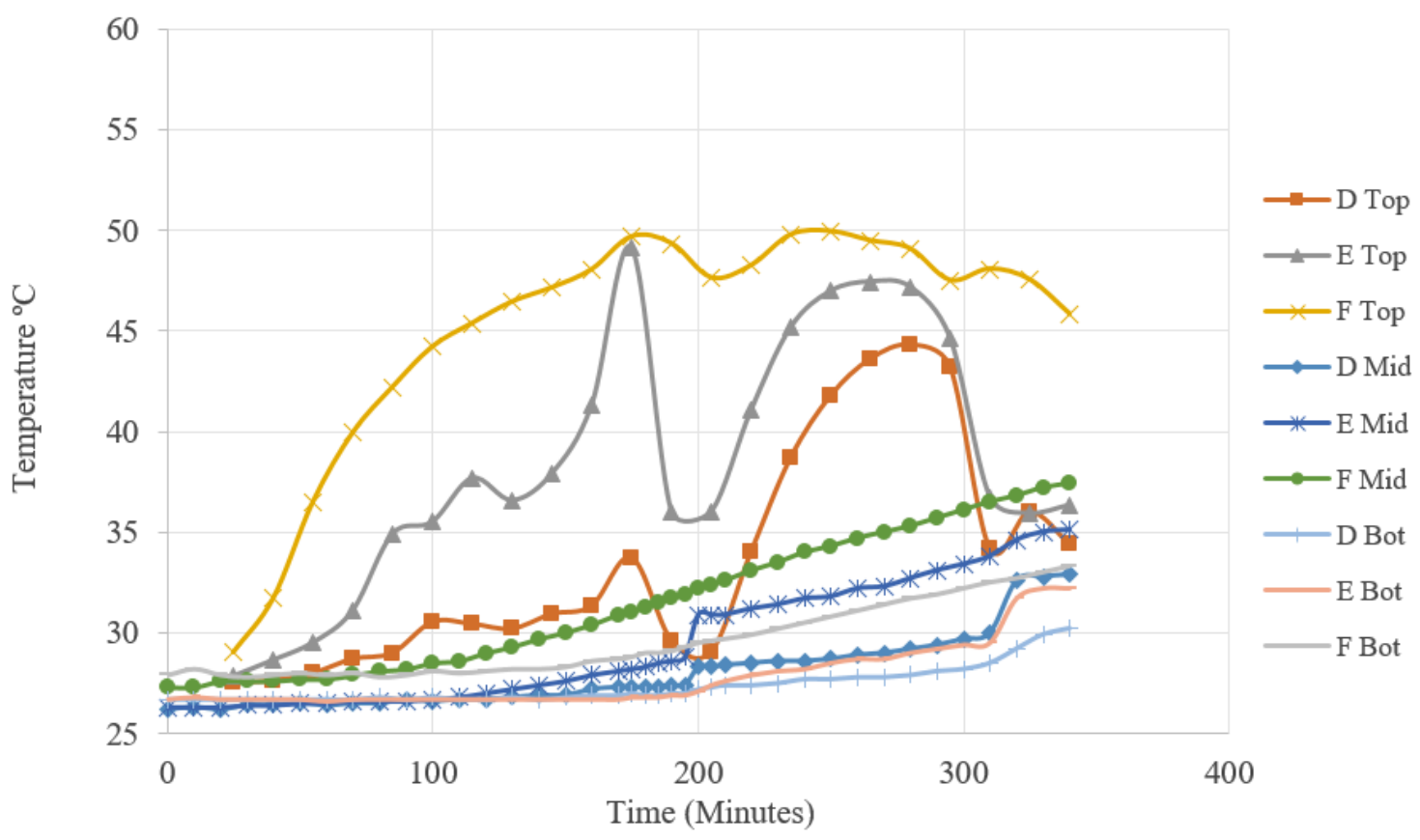

Figure 4: Top, middle and bottom temperatures recorded for the three sections using the 4/1 mix design in January 2016. $\mathrm{F}$ is the control. $\mathrm{D}$ and $\mathrm{E}$ had water added. 


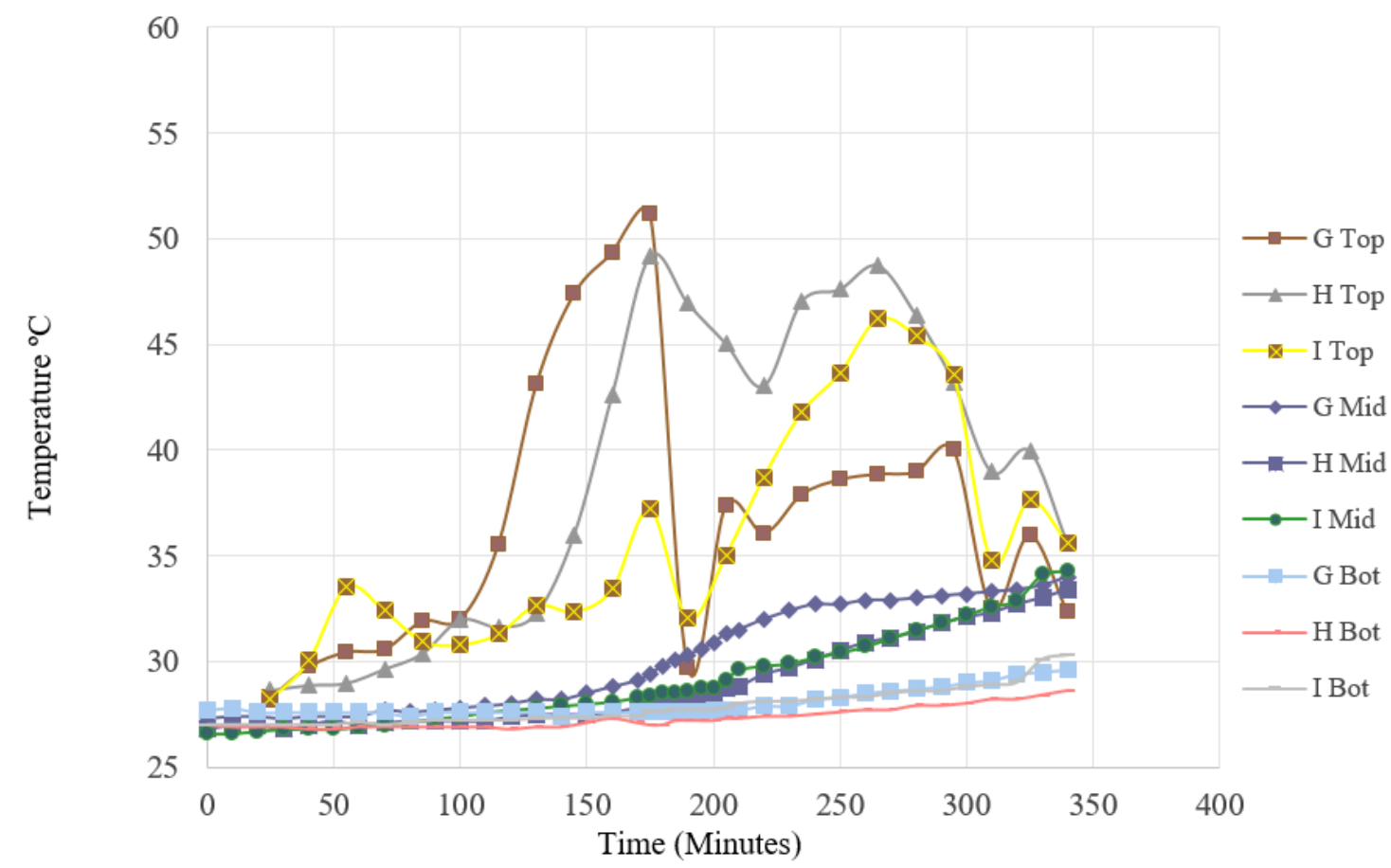

Figure 5: Top, middle and bottom temperatures recorded for the three sections using the 7.1/1 mix design in January 2016. $\mathrm{H}$ is the control. $\mathrm{G}$ and I had water added.

\section{DISCUSSION}

Pervious concrete is very variable with respect to its properties. Not only can the mix design impact the porosity and density, but also the compactive effort. Pervious concrete has variable porosity horizontal depending on the compaction and placement techniques, and a unique vertical porosity distribution with typically lower porosities near the top which progressively get larger deeper down due to the surface compaction used during placement [13]. Adding in the variability with the weather, the solar radiation and shading changes, etc. make it very difficult to develop a simple model for the heat gain in the system, even without water being added. However, some trends can be evaluated. In general, heat gain in a small portion of pervious concrete is proportional to the change in temperature. Assuming that the densities of the three mixes and where the sensors are located in the sections are similar, then some simplified models can be made. Of course, adding water does add additional mass and heat capacity. This general trend can be seen in Figure 6, which plots the middle temperatures at all nine sections for most of the experiment. The visual changes from right before the first wetting until the end of the experiment after the second wetting are very similar. 


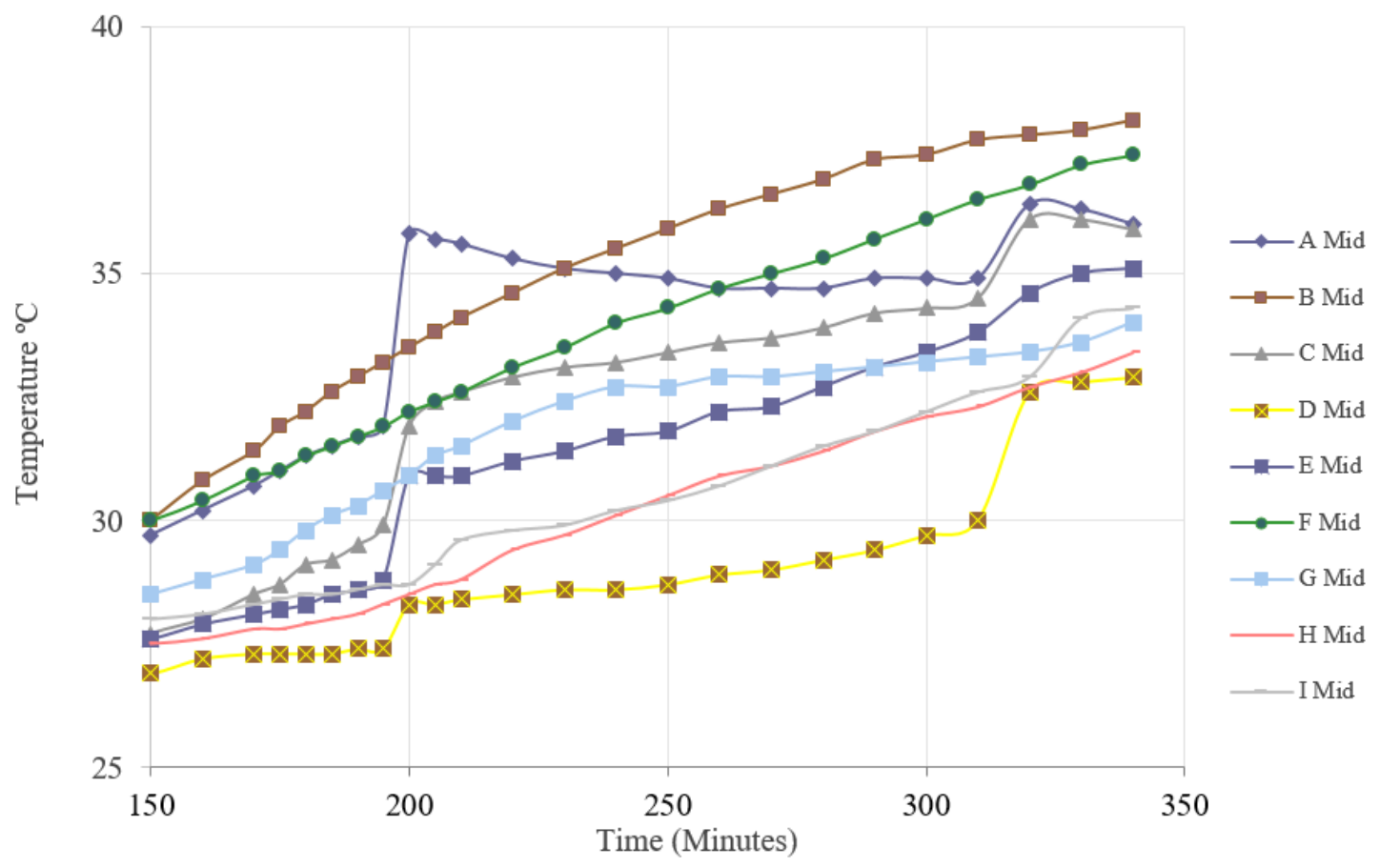

Figure 6: Temperatures in the middle locations for all nine sections from time at 150 minutes until the end of the experiment.

Now, looking only at the changes from before the addition of water until the end of the experiment, then it is reasonable to assume that little water is left in the system. This has been done for all the 18 sensor locations in Table 1, with the control locations highlighted. The differential temperature is calculated and listed in Table 1 from the time just before the addition of the simulated rain event at 175 minutes until the end of the experiment at 340 minutes for all the middle locations. This can also be seen visually for the middle locations as depicted in Figure 6. Table 1 also has these differential values for the bottom locations in all nine sections of the pervious concrete studied. Using the data from Table 1, if the average temperature change of the six middle sensors which participated in the water test (5.9) are compared to the average of the three middle sensors that were the controls (6.1), then it appears that there is a little more heat retained in the middle levels of the pervious concrete for the control sections. At the same time a similar comparison for the bottom sensors shows an average of 3.3 for the test locations, and an average of 2.6 for the control locations. This implies that there is a little more heat retained near the bottom for the test sections. Both of these trends in Table 1 make sense. Due to being closer to the surface and therefore warmer, the middle sections received more water and had more opportunity to have these waters evaporate. This would result in a slightly lower temperature after most of the water evaporates. Conversely, for the bottom locations, being lower, and thus cooler, there would probably still be some water there that had not evaporated with some of the heat in the water remaining. If one looks at both locations together, it appears that the addition of heat through the transport of water into the system has a negligible impact overall, with the porous nature of the material providing mitigation of the heat island effect under both dry and wet conditions. Statistical analyses and additional data from other experimental tests and heat modeling would aid in validating this conclusion. 
Table 2: Temperature gains in the pervious concrete (Controls are highlighted.).

\begin{tabular}{|c|c|c|c|c|}
\hline LOCATION & $\begin{array}{l}\text { TEMPERATURE A } \\
175 \text { MINUTES (으) }\end{array}$ & $\begin{array}{l}\text { AT TEMPERATURE AT } \\
300 \text { MINUTES }\left({ }^{\circ} \mathrm{C}\right)\end{array}$ & $\begin{array}{l}\text { TTEMPERATURE } \\
\left.340 \text { MINUTES ( }{ }^{\circ} \mathrm{C}\right)\end{array}$ & $\begin{array}{l}\text { ATTEMPERATURE CHANGE } \\
175-340 \text { MINUTES }\left({ }^{\circ} \mathrm{C}\right)\end{array}$ \\
\hline A Middle & 31.0 & 34.9 & 36.0 & 5.0 \\
\hline B Middle & 31.9 & 37.4 & 38.1 & 6.2 \\
\hline C Middle & 28.7 & 34.3 & 35.9 & 7.2 \\
\hline D Middle & 27.3 & 29.7 & 32.9 & 5.6 \\
\hline E Middle & 28.2 & 33.4 & 35.1 & 6.9 \\
\hline F Middle & 31.0 & 36.1 & 37.4 & 6.4 \\
\hline G Middle & 29.4 & 33.2 & 34.0 & 4.6 \\
\hline H Middle & 27.8 & 32.1 & 33.4 & 5.6 \\
\hline I Middle & 28.4 & 32.2 & 34.3 & 5.9 \\
\hline A Bottom & 27.4 & NA & 30.6 & 3.2 \\
\hline B Bottom & 26.7 & NA & 28.5 & 1.8 \\
\hline C Bottom & 27.0 & NA & 30.1 & 3.1 \\
\hline D Bottom & 27.0 & NA & 30.2 & 3.2 \\
\hline E Bottom & 26.8 & NA & 32.2 & 5.4 \\
\hline F Bottom & 28.8 & NA & 33.3 & 4.5 \\
\hline G Bottom & 27.6 & NA & 29.6 & 2.0 \\
\hline H Bottom & 27.0 & NA & 28.6 & 1.6 \\
\hline I Bottom & 27.6 & NA & 30.3 & 2.7 \\
\hline $\begin{array}{l}\text { Average Middle } \\
\text { Wetted }\end{array}$ & NA & NA & NA & 5.9 \\
\hline $\begin{array}{l}\text { Average Middle } \\
\text { Control }\end{array}$ & NA & NA & NA & 6.1 \\
\hline $\begin{array}{l}\text { Average Bottom } \\
\text { Wetted }\end{array}$ & NA & NA & NA & 3.3 \\
\hline $\begin{array}{l}\text { Average Bottom } \\
\text { Control }\end{array}$ & NA & NA & NA & 2.6 \\
\hline
\end{tabular}

NA: Not applicable

A paired, 2-tailed t-test was performed on the pairs of tests with their controls in the middle of the pervious concrete for the testing period from 175 minutes to 340 minutes for the January 2016 experiments, resulting in a value of 0.62 , indicating that based on the number of data points, the change in temperature is not significantly different between the controls and the wetted tests in the middle. Note that for the January 2016 tests this is after two sun shower wettings in a hot afternoon, a rare, but possible occurrence. However, the January 2016 experiments also provide information for a single sun shower.

A similar statistical analysis can be performed on the change in temperature from before the first wetting until just before the second wetting. The values for the January 2016 experiments are also listed in Table 1 at 300 minutes for the middle sensors, just before the second wetting. Similar values can be taken from Figure 1 for the April 2015 experiments, and have been done from a time 40 minutes into that experimental procedure until a similar 125 minutes later. This provides an additional 2 pairs of data for a total of 8 pairs. A paired, 2 tailed t-test was then performed on the pairs of tests with their controls for the middle of the pervious concrete for the single wetting tests on both occasions. This resulted in a value of 0.05 , which indicates that there 
is almost a significant difference between the pairs, with the test sections actually cooler than the control sections.

\section{CONCLUSIONS}

In summary, as previously studied, pervious concrete systems can serve to mitigate the heat island effect by their porous nature, which provides insulation against more rapid heat transfer by conduction in the concrete into the subsurface. In addition, pervious concrete systems can provide for evaporative cooling when there is water in the system, and as this current research shows, this cooling is more than sufficient to offset the addition of heat as transported into the system by heated stormwater under the hot summer conditions as studied herein.

\section{ACKNOWLEDGMENTS}

We would like to thank the Federal University of Rio Grande do Sul (UFRGS), Washington State University and the Brazil-U.S. Fulbright Program for providing facilities and funding for this research. We would also like to thank the many students, faculty and staff at UFRGS in the Laboratory for Testing and Modeling of Structures (LEME) for their efforts installing the pervious concrete, modifying the equipment and collecting the data presented herein.

\section{BIBLIOGRAPHY}

[1] ASAEDA, T., CA, V.T., WAKE, A., "Heat Storage of Pavement and Its Effect on the Lower Atmosphere", Atmospheric Environment, v. 30, n. 3, pp. 413-427, 1996.

[2] MARCEAU, M., VAN GEEM, M., Solar Reflectance of Concretes for LEED Sustainable Site Credit: Heat Island Effect, Publication SN2982, Portland Cement Association, Skokie, IL, USA, 2007.

[3] HASELBACH, L., The Engineering Guide to LEED-New Construction: Sustainable Construction for Engineers, 2 ed,. New York, USA, McGraw-Hill, 2010.

[4] LI, H., JHARVEY, J.T., HOLLAND, T.J., KAYHANIAN, M., "The use of reflective and permeable pavements as a potential practice for heat island mitigation and stormwater management", Environ. Res. Lett., v. 8, 2013.

[5] WILLIAMS, A.P., SCHWARTZ, R.E., IACOBELLIS, S., et al., "Urbanization causes increased cloud base height and decreased fog in coastal Southern California”, Geophys. Res. Lett., v. 42, pp. 1527-1536, 2015.

[6] HASELBACH, L., GAITHER, A., "Preliminary Field Testing: Urban Heat Island Impacts and Pervious Concrete", In: Proceedings of the NRMCA Concrete Technology Forum: Focus on Sustainable Development, Denver CO, USA, May 2008.

[7] KEVERN, J., SCHAEFER, V., WANG, K., "Temperature Behavior of Pervious Concrete Systems", Transportation Research Record: Journal of the Transportation Research Board, n. 2098, 2009.

[8] HASELBACH, L., BOYER, M., KEVERN, J., et al., "Cyclic Heat Island Impacts on Traditional versus Pervious Concrete Pavement Systems", Transportation Research Record, Journal of the Transportation Research Board, n. 2240, pp. 107-115, 2011.

[9] KEVERN, J., HASELBACH, L., SCHAEFER, V., "Hot Weather Comparative Heat Balances in Pervious Concrete and Impervious Concrete Pavement Systems", Journal of Heat Island Institute International, v. 7, n. 2, 2012

[10] BALBO, J.T., SEVERI, A.A., "Thermal Gradients in Concrete Pavements in Tropical Environment: Experimental Appraisal", Transportation Research Record, Journal of the Transportation Research Board, n. 2560, 2002.

[11] NEMIROVSKY, E.M., WELKER, A.L., LEE, R., “Quantifying Evaporation from Pervious Concrete Systems: Methodology and Hydrologic Perspective”, J. Irrig. Drain Eng., v. 139, n. 4, pp. 271-277, 2013.

[12] LORENZI, A., HASELBACH, L., SILVA FILHO, L.C.P., "Field data for heat island mitigation by pervious concrete in Porto Alegre", In: Proceedings of the 3rd International Conference on Best Practices for Concrete Pavements, Bonito, Brazil, IBRACON - ISSN 2175-8182. 3PAV20150016, Oct. 28-30 2015.

[13] HASELBACH, L. FREEMAN, R., "Vertical Porosity Distributions in Pervious Concrete Pavement", ACI Materials Journal, v. 103, n. 6, pp. 452-458, 2006. 